LIAMES 4 - pp. 129-146, Primavera 2004

Lucy Seki

(UNICAMP)

\title{
Aspectos da Morfossintaxe Krenak: Orações Independentes
}

\section{RESUMO}

O trabalho apresenta uma análise preliminar das orações independentes (declarativas, interrogativas, imperativas) da língua Krenak, única representante atual da família Botocudo (Borum), e que se encontra em avançado processo de extinção. A análise se baseia em dados coletados a 04 falantes adultos, um residente na Aldeia Krenak (rio Doce, MG), e três no P.I. Vanuíre (SãoPaulo), no período de janeiro de 1980 a janeiro de 1982. O trabalho aborda ainda a questão das classes de palavras e a estrutura da locução nominal da língua. PALAVRAS-CHAVE Krenak; Botocudo; Borum; oração independente.

\section{RESUMEN}

El trabajo presenta un análisis preliminar de las oraciones independientes (declarativas, interrogativas, imperativas) de la lengua Krenak, única representante actual de la familia Botocudo (Borum), y que se encuentra en avanzado proceso de extinción. El análisis se basa en datos recogidos junto a cuatro hablantes adultos, uno residente en la aldea Krenak (Rio Doce, MG) y tres en el Posto Indígena Vanuíre (S. Paulo), en el período comprendido entre enero de 1980 hasta enero de 1982. El trabajo trata, también, sobre la cuestión de las clases de palabras y la estructura de la locución nominal en la misma lengua.

Palabras llave Krenak; Botocudo; Borum; oración independiente.

\section{INTRODUÇÃO}

O Krenak / Nakrehé é uma língua da família Botocudo (Borum), classificada como pertencente ao tronco Macro-Jê. É o único membro ainda existente dessa família, que foi no passado bastante numerosa, mas cujos grupos integrantes desapareceram sem que nenhuma de suas línguas/dialetos fosse convenientemente descrita ou documentada. De fato, os materiais lingüísticos existentes não incluem informações mais completas sobre a estrutura gramatical do Botocudo, consistindo, em sua maioria, de listas vocabulares bastante limitadas, com transcrição via de regra inadequada e que, salvo raras exceções (Guérios, 1943; Manizer, 1915), nada podem contribuir para o conhecimento da gramática da língua (cf. Seki, 1990 para uma análise desses materiais). 
Os representantes Botocudo atuais são geralmente referidos com o nome de Krenak denominação de um dos subgrupos Botocudo e de seu local tradicional às margens do rio Doce, em Minas Gerais. Embora essa denominação tenha se generalizado, a comunidade Krenak inclui representantes e/ou descendentes de outros subgrupos Botocudo, particularmente Nakrehé. A comunidade como um todo acha-se dispersa e apresenta um alto grau de miscigenação com não Botocudos (índios e não índios). Já há muito não existem falantes monolíngues da língua nativa, e dentre todos os representantes atuais estima-se em menos de dez o número de adultos que ainda mantêm, em diferentes graus, um domínio da mesma. A língua encontra-se, assim, nos limites de um desaparecimento completo.

Esta comunicação apresenta resultados parciais de um trabalho maior de análise e descrição do Krenak. Nela propomos uma descrição de cunho funcional-tipológico de aspectos morfossintáticos da língua, feita com base em dados coletados a quatro falantes nativos, no decorrer de cinco visitas muito breves e intermitentes à Aldeia Krenak do rio Doce, em Minas Gerais, e ao Posto Indígena Vanuíre, em São Paulo, realizadas no período de janeiro de 1980 a janeiro de 1982, como parte do desenvolvimento de um projeto mais amplo voltado para a de documentação da língua e história do povo.

A situação particular do povo Krenak e o estado em que se encontra a língua, o número muito limitado de informantes potenciais e sua dispersão, o problema de avaliar o grau de conhecimento dos falantes e, por conseguinte, o grau de completude do material analisado e, principalmente, a impossibilidade de obtenção de textos (Seki, 1984) são algumas das dificuldades que enfrentamos na realização do trabalho de campo e que se colocam à analise e descrição da língua. Obviamente, a análise muito se beneficiaria com um novo contato com os falantes que, entretanto, são pouco receptivos. Não obstante, acreditamos que as observações aqui apresentadas podem contribuir para um melhor conhecimento da língua Krenak e da família Botocudo, sem dúvida uma das menos conhecidas do Brasil, e também para estudos comparativos históricos e tipológicos do tronco Macro-Jê e de outras línguas indígenas brasileiras.

Uma motivação maior para a retomada do trabalho com a língua relaciona-se ao fato de estar sendo desenvolvido um projeto de educação entre os Krenak e ao grande desejo que estes manifestam no que se refere à recuperação de sua cultura e de sua língua. Esperamos que o trabalho possa constituir-se em uma contribuição para essa finalidade. Tendo em vista esse objetivo, incluímos como anexo uma reprodução de desenhos feitos pelo etnólogo russo H. H. Manizer durante sua estadia entre os Krenak, em 1915, referentes a pintura corporal, cortes de cabelo e abrigos. Os originais fazem parte dos manuscritos do mencionado autor, conservados no Arquivo do Museu de Antropologia e Etnografia "Pedro o Grande" (Kunstkamera) da Academia de Ciências da Rússia, e que tivemos a oportunidade de consultar em julho de 2001.

Dos quatro informantes principais com os quais trabalhamos, Sebastiana de Souza (S) residia na Aldeia Krenak, tinha cerca de 70 anos na época da pesquisa e era apontada em toda a comunidade como a pessoa que melhor conhecia a língua. Sebastiana, que veio a falecer em 1982, identificava-se como pertencente ao grupo Ngut-krak. Os três outros falantes, todos residentes no Posto Indígena Vanuíre, adultos, com idade entre 40 e 50 anos, foram José Anato (JA), sobrinho de Sebastiana, Antônio Jorge (AJ) e Jovelina (J), todos casados com não Botocudos. Tivemos ainda acesso a uma fita gravada por Benedita Aparecida C. Araújo com Maria Sônia Krenak(MS). 
Iniciaremos com uma apresentação de algumas características gerais da língua, das classes de palavras e dos critérios usados para distinguí-las, para em seguida tratar as orações independentes da língua.

Na transcrição dos dados apresentados no trabalho utilizamos uma transcrição fonética mais ampla, e não propriamente fonológica. O quadro dos principais sons do Krenak vem apresentado a seguir.

\begin{tabular}{|c|c|c|c|c|c|c|c|}
\hline \multirow[b]{2}{*}{$\mathrm{p}$} & \multirow[b]{2}{*}{$\mathrm{t}$} & \multirow[b]{2}{*}{$\mathrm{t} \int$} & \multirow[b]{2}{*}{$\mathrm{k}$} & \multirow[b]{2}{*}{$?$} & \multicolumn{3}{|c|}{ Quadro de sons } \\
\hline & & & & & $\mathrm{i}$ & $\dot{\dot{1}}$ & $\mathrm{u}$ \\
\hline $\mathrm{mb}$ & nd & nd3 & $\mathrm{gg}$ & & $\mathrm{e}$ & ə & o \\
\hline m & n & $\mathrm{j}_{\circ}$ & g & & $\varepsilon$ & $\mathrm{a}$ & 0 \\
\hline $\mathrm{m}$ & $\mathrm{n}$ & $\mathrm{n}$ & $\eta$ & & & & \\
\hline $\mathrm{w}$ & & $j / 3$ & $\mathrm{~h}$ & & $\tilde{1}$ & $\widetilde{\mathbf{t}}$ & $\tilde{u}$ \\
\hline & r & & & & $\tilde{\mathrm{e}}$ & $\tilde{a}$ & $\tilde{o}$ \\
\hline
\end{tabular}

\section{CARACTERÍSTICAS GERAIS E CLASSES DE PALAVRAS EM KRENAK}

É possível distinguir em Krenak as classes de Nome, Verbo, Advérbio, Pronome, Demonstrativo e Partícula.

Os nomes apresentam a categoria de posse e sintaticamente se distinguem dos Verbos pela possibilidade de ocuparem as posições de sujeito, objeto de verbos e de posposições.

Há duas subclasses de verbos: a dos ativos e descritivos, sendo que os membros de ambas ocorrem tipicamente como predicados, porém os ativos, mas não os descritivos, manifestam as categorias de tempo, aspecto e modo.

Pelo número de argumento que admitem, os verbos ativos se subdividem em intransitivos e transitivos. Os verbos descritivos são também intransitivos.

Nomes e verbos descritivos têm em comum o mesmo marcador de primeira pessoa do singular, o que os distingue dos verbos ativos - transitivos e intransitivos, que recebem marcador distinto.

Os verbos descritivos, desprovidos de flexão pessoal, podem ocorrer como modificadores de verbos.

Como em outras línguas, os Advérbios constituem uma classe heterogênea de elementos, incluindo palavras locativas, temporais, quantificacionais, qualificacionais e termos para números.

Sintaticamente, dependendo da subclasse, os advérbios ocorrem como predicado em orações não verbais, como adjunto em outros tipos de orações e como modificadores de verbos. Nesta última função geralmente precedem o verbo, exceto no caso de advérbios oriundos de descritivos, que ocupam posição inversa.

O Krenak é uma língua posposicional. As posposições vêm sempre precedidas de seu objeto e são usadas para expressar distintas funções semânticas locais e não locais.

Distinguem-se três formas básicas de Demonstrativos segundo o grau de proximidade do referente em relação ao falante (não foi possível constatar a relevância de outros parâmetros, como visibilidade, audibilidade, proximidade em relação ao ouvinte, etc.). Sintaticamente os demonstrativos ocorrem como pronomes, como modificadores de nomes e como advérbios 
Na classe de Pronomes incluímos os pronomes pessoais, interrogativos e indefinidos.

O sistema de codificação de pessoa em Krenak é uma área que apresenta problemas para a análise. Sabe-se que tipologicamente o sistema pronominal em línguas (Macro-)Jê é complexo. Por outro lado, conforme referido, o contato com os falantes foi breve, há uma grande variação na pronúncia de certos itens, não foi possível obter textos coesos e também, com freqüência, houve dificuldade em obter dos falantes o equivalente do enunciado solicitado em Português. Usualmente ocorria a substituição das pessoas do enunciado, sendo as mesmas focalizadas sob o ponto de vista do falante. Assim, por exemplo, ao solicitar o equivalente de "você me viu", obtinha-se o equivalente de "eu vi você", ou então, uma réplica à questão. Houve casos em que o falante teve dificuldade em fornecer os dados porque a pergunta não correspondia a fatos concretamente reais. Por exemplo, quando solicitado o equivalente de "minha canoa" (tendo em vista verificar a distinção entre posse inalienável e alienável, bem como a hipótese de que uma dada forma pronominal estaria condicionada fonologicamente), houve um certo constrangimento, porque, como se esclareceu em seguida, o falante não possuía de fato uma canoa (Seki, 1984).

Por outro lado, deve ser levada em conta a provável incorporação de diferenças dialetais. Assim sendo, as formas e sua interpretação aqui apresentadas devem ser consideradas como preliminares.

O sistema pronominal inclui um conjunto de pronomes livres e um conjunto de formas presas. Os pronomes livres apresentam distintas formas para a primeira, segunda e terceira pessoas do singular e não singular. Na esfera da primeira pessoa não singular há distintas formas que podem ser interpretadas como inclusiva (kinij) e exclusivas (Đgren, ningren), sendo que as duas últimas parecem expressar uma distinção 'dual / plural'.

As formas pronominais livres aparecem resumidas no quadro abaixo:

\begin{tabular}{|c|c|c|}
\hline & Formas Livres & Formas Presas \\
\hline $1^{a}$ p. sg. & 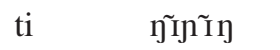 & 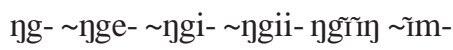 \\
\hline $2^{a}$ p. sg. & huti $\sim$ hoti & $\mathrm{a}-\sim \tilde{\mathrm{a}} \sim \mathrm{h}-\sim \mathrm{hi}$ \\
\hline $3^{\mathrm{a}}$ p. sg & ñãy & ki- $\sim$ k- $\sim$ hi- $\sim$ j- $\sim \varnothing$ \\
\hline $1^{\mathrm{a}} \mathrm{p}$. inclusiva & 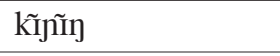 & \\
\hline $1^{\mathrm{a}} \mathrm{p}$. exclusiva & nĩngren & \\
\hline $2^{\mathrm{a}} \mathrm{p} . \mathrm{pl}$. & ãndzuk & \\
\hline $3^{\mathrm{a}} \mathrm{p} . \mathrm{pl}$ & n̊ãngren ãggren & \\
\hline
\end{tabular}

O uso dessas formas não está totalmente claro. As da primeira coluna geralmente ocorrem como sujeito de verbos ativos e descritivos, sendo que algumas - a de $3^{\mathrm{a}} \mathrm{p}$. sg. e as de $1^{\mathrm{a}}, 2^{\mathrm{a}} \mathrm{e}$ $3^{a}$ plural, aparecem nos dados com a função de objeto direto. Contudo, aparecem também codificando o possuidor. As formas da segunda coluna são usadas para codificar o possuidor, e certos alomorfes da primeira, da segunda e da terceira pessoas ocorrem como sujeito de descritivos e como objeto de verbos e posposições. O uso de elementos pronominais será mostrado nos exemplos dados no decorrer do trabalho. 
133

Na locução genitiva o modificador (possuidor) precede o Núcleo (item possuído). Outros modificadores do Nome - Nomes, Demonstrativos, Descritivos, Numerais, seguem o núcleo (Seki, 2000).

\section{ESTRUTURA DASSENTENÇASSIMPLESEMKRENAK.}

Serão descritas neste item as sentenças declarativas, interrogativas e imperativas e seus subtipos.

Distinguem-se tentativamente os seguintes tipos de sentenças declarativas simples no Krenak: orações verbais intransitivas ativas, intransitivas descritivas e transitivas e orações não verbais identificadoras, locativas/existenciais e possessivas.

A distinção entre esses tipos e subtipos de orações baseia-se nas classes de palavras que manifestam o predicado, na distribuição de elementos pronominais e na presença / ausência obrigatória de constituintes.

\subsection{Orações verbais}

\subsubsection{Orações intransitivas ativas}

São orações com predicado verbal intransitivo ativo, nas quais está presente apenas um argumento, expresso por uma locução nominal ou pronominal:

(01) ti mũy nuk ne?

eu ir Neg Fut

eu não irei
(02) n̊ãntõndon ti puk ? Ĩ criança ? chorar PresCont a criança está chorando

(03) hoti a-ñ̃̃ kurãn nuk você 2 sg-vir Desid Neg você não quer vir?

\subsubsection{Orações descritivas}

São orações intransitivas com apenas um argumento, e cujo predicado é um verbo descritivo. Distinguem-se dos outros tipos de orações pelo fato de não admitirem o marcador de sujeito de primeira pessoa singular ti. Além disso, não aparecem no corpus com o morfema de presente contínuo ?i:

(04) ทi Ĩך ton

eu feio/mau

eu sou feio / mau
(05) a-rõn

2sg-alto / comprido

você é alto 
134

(06) kuparak mikarãn

onça pesada

(07) wati jõm

milho verde

a onça é pesada

o milho está verde

(08) ggi ĩ ñak tõndon

eu terra pequena

minha terra é pequena

Foram registradas construções com descritivos nas quais aparece um morfema t $\varepsilon$ ou $\varepsilon$, como nos exemplos abaixo:

(09) mbrogn te prugn

caminho? reto

(S)

(10) ก̊ã̃ $\varepsilon$ rõn(AJ)

ele ? alto

o caminho é reto

ele é alto

Contudo, esses elementos aparecem também em outros tipos de construções, e sua significação não está clara, não se excluindo a hipótese de que sejam empréstimo do Português.

\subsubsection{Orações transitivas}

São orações que têm como predicado um verbo transitivo. Distinguem-se das intransitivas pela presença de uma locução nominal em função de objeto direto, a qual ocorre precedendo o verbo e seguindo o sujeito:

(11) ti krak jaha ? eu faca procurar PresCont eu estou procurando a faca
(12) ñãntõndon kuparak pip

criança onça ver

a criança viu a onça

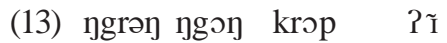

cobra cachorro morder PresCont

a cobra está mordendo o cachorro

\subsubsection{Orações não verbais identificadoras}

Foram registrados dois tipos de construções que exprimem identidade ou função/ papel.

\subsubsection{Orações equativas}

Consistem de duas locuções nominais não marcadas, uma das quais tem função predicativa e a outra é o sujeito da predicação.

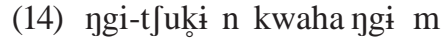
1sg-marido homem este / aqui meu marido é este homem
(15) hoti kĩnora? você mulher não índia você é mulher não índia 


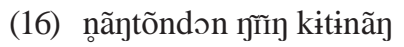

criança 1 sg neta

a criança é minha neta

\subsubsection{Orações com elemento cópula}

São orações não verbais que também exprimem identidade, função, papel, nas quais o sujeito nominal ou pronominal vem marcado com o morfema cópula -wa, formalmente idêntico a um morfema com significação locativa/direcional (cf. adiante). O elemento pronominal sujeito pode ser uma forma livre ou presa:

(17) g -wa mburũy

1sg-Cop índio

eu sou índio
(18) n̊ãy-wa mburũy nuk

[nãã i-ũndzak-wa anat]

ele-Cop índio Neg

ele não é índio

Confiram-se também os seguintes exemplos coletados por Guérios (1944) e aqui transcritos conforme notação do original, sendo indicados, entre colchetes, o provável equivalente em nossa transcrição:

(19) goá kapitão

eu sou capitão

(20) goá Pak

eu sou Pak

(21) nan juják uá Anát

o nome dele é Anat [ฤg-wa kapitãw]

1sg-Cop capitão

'eu sou capitão

[ng -wa Pak]

1sg-Cop Pak

eu sou Pak

[nãã i-ũndzak-wa anat]

ele 3-nome-Cop Anat

o nome dele é Anat

\subsubsection{Orações Locativas / Existenciais}

São orações que têm como complemento predicativo um advérbio ou locuções posposicionais. Exprimem locação e/ou existência.

(22) Pamãngut angWĩn comida não existente não tem comida

(24) jgii-kin huwãn 1sg -pai longe meu pai está longe
(23) $\mathrm{t} \int \tilde{I} \eta$ nãwit gi m carne muito aqui aqui tem muita carne / caça

(25) marot katñck pombi arroz panela dentro o arroz está dentro da panela 
136

(26) mĩnãn ti mbok jãwit

rio Loc peixe muito

(27) ã-ndjẽm-wa prik jãwit

2sg-casa-Loc formiga muito

no rio tem muito peixe

em tua casa tem muita formiga

Como mostram os último exemplos, o complemento predicativo pode preceder o nominal sujeito.

\subsubsection{Orações possessivas}

Foram registrados os seguintes tipos de construções que exprimem posse:

\subsubsection{1.}

O possuidor, expresso por elemento pronominal (não temos registro de exemplos com nominais) tem posposto o morfema we, formalmente idêntico ao morfema comitativo:

(28) jg-we kõn put $\int i k$

$1 \mathrm{sg}$ - Indef um

eu tenho uma coisa

\subsubsection{2.}

O nome ou elemento pronominal que exprime o possuidor tem posposto o morfema wãn:

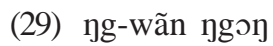

1sg-Poss cachorro

eu tenho cachorro

o cachorro é meu

(30) ̉gon ggi m noãytõndon wãn

cachorro este criança Poss

este cachorro é da criança

\subsubsection{3.}

O elemento pronominal que exprime o possuidor é seguido pelo morfema -iuk, formalmente idêntico ao benefactivo:

(31) n̊ãy-iuk not jãwit

ele- dinheiro muito

ele tem muito dinheiro 
Em todos os tipos de orações declarativas a negação é assinalada pelo morfema nuk, posicionado após o verbo ou predicado nominal:
(32) ti jgri nuk ne? eu cantar Neg Fut eu não cantarei
(33) ñãy rehe nuk ele bom Beg ele não é / está bom

Além dos constituintes nucleares descritos nos itens anteriores, a oração pode incluir outros constituintes - objeto indireto, benefactivo, adjunto, etc, os quais são aqui considerados de modo geral como oblíquos, dado que não dispomos, no momento, de critérios seguros (exceto, talvez, a ordem de ocorrência, cf. adiante) que nos permitam estabelecer uma distinção formal entre eles. Assim sendo, não incluímos aqui orações bitransitivas ou intransitivas estendidas como tipos oracionais distintos.

\subsubsection{Ordem dos constituintes}

Nas orações intransitivas o sujeito precede consistentemente o verbo. Nas orações transitivas a ordem também consistente dos constituintes é Sujeito - Objeto direto Verbo (SOV). O objeto indireto, codificado pela posposição pə ( mbə) usualmente ocorre entre o sujeito e o objeto direto:

(34) Tãm họ ก̃̃

Indef queimar PresCont

algo [a árvore] está queimando

(35) nõ̃ytõndon kupirik zuk ndzorot T̃̃

(SOV)

menino macaco rabo puxar PresCont

O menino está puxando o rabo do macaco

(36) ti noạ- pə kõn ?ũm nع?

(SOiOV

eu ele-Dat Indef dar Fut

eu darei isto para ele

(37) hoti ทі̃--mbə mĩjã̃ ?ũm

(SOiOV)

você 1sg-Dat água dar

você me dá água

Também entre o sujeito e o objeto direto ocorrem constituintes marcados com -nuk/-iuk/ -uk, que temos interpretado como benefactivo:

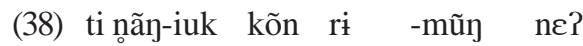
eu ele-Bem Indef CausCom-ir Fut eu levarei isto para ele 
138

(39) ti $\mathrm{h}$-uk kõn ri -ñ̃n eu 2sg-Bem Indef CausCom-vir eu trouxe isto para você

Os adjuntos temporais tendem a ocorrer na posição inicial da oração ou após o sujeito:

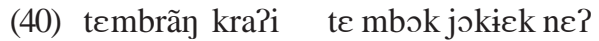
amanhã não índio ? peixe pescar Fut amanhã o não índio vai pescar

(41) ñãy $\varepsilon$ tعmbrãy ndzak ti mũz sãw paulu-wa ele ? amanhã outro ? ir São Paulo-Dir depois de amanhã ela irá para São Paulo

Locativos e outros constituintes oblíquos foram registrados ou em posição final de oração, ou precedendo o verbo, como no dado a seguir:

(42) ti mũy ne ã -ndjẽm-wa eu ir Fut 2sg-casa -Dir eu irei para a tua casa

(43) noãytõndon ti mũy i-spu-we criança ? ir 3-mãe-Com a criança vai com a mãe dela

(44) katn̊kk nakuð̃ٓ j-ukupi jep (S) panela fogão 3-sobre estar sentado a panela está em cima do fogão

(45) ggð ki-jẽm pombi wip (S) cachorro 3 -casa dentro estar deitado o cachorro está deitado dentro da casa

(46) katn̊k nep fugãw ti (J) panela sentado fogão Loc a panela está sobre o fogão

\subsection{Orações Interrogativas}

\subsubsection{Perguntas polares}

As orações que exprimem perguntas sim-não são estruturalmente semelhantes às declarativas, sendo marcadas por entonação ascendente, com o ponto mais alto na última sílaba tônica do enunciado, o que as distingue das declarativas, nas quais o contorno entonacional é descendente: 
(47) a -rehe?

2sg-bom

você está bom?

(48) hoti a -nĩn ne?

você 2 s-vir Fut

você virá?

(49) hoti ฤg -we mũ̄ nع?

você 1 sg-Com ir Fut

você vai comigo?

\subsubsection{Perguntas alternativas}

Nas perguntas alternativas ocorrem duas ou mais locuções (ou orações), as quais descrevem as diferentes possibilidades. As locuções (ou orações) apresentam contorno ascendente, exceto a última, que tem contorno descendente. Podem vir simplesmente justapostas, porém é mais freqüente que todas, exceto a primeira venham precedidas pelo morfema , um possível empréstimo da conjunção ou do Português:

(50) ggutkrak ndzẽm huwaך narẽ

ngutkrat casa longe perto

a morada dos ngutkrak fica longe ou perto?

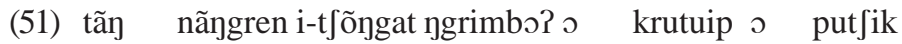
quanto eles 3-canoa duas ou três ou uma quantas canoas eles têm: duas, três ou uma?

\subsubsection{Perguntas com palavras interrogativas}

As principais palavras interrogativas do Krenak são as seguintes:

(52) inã quem'

?am nimm 'o que'

kõním 'qual, como'

hakre 'onde'

tãn 'quantos(s)'

Pamnĩmwe 'por que'

A forma inãy é usada com referência a seres animados, e ?amñ̃m, a seres inanimados. Em Pamnĩm we 'porque' depreende-se claramente o morfema we, que ocorre em outros contextos expressando finalidade. As palavras Pamnĩm e kõnĩm são provavelmente constituídas, respectivamente, dos indefinidos ?am 'algo, coisa' e kõn 'nome indefinido, 
140

genérico' e de um elemento (partícula clítica) interrogativo núm. Em hakre 'onde' é possível identificar um morfema interrogativo (?) hak e o morfema kre 'aqui, lugar'. Os seguintes dados do Botocudo encontrados em outras fontes corroboram a análise das palavras interrogativas do Krenak:

(53) há(k) krák nim 'qual faca?' (Guérios, 1944)

faca

(54) hak

'qual, onde, o que’ (Rudolph, 1909)

Não obtivemos de nossos colaboradores o equivalente para a palavra interrogativa 'quando'. Guérios registrou as formas seguintes para 'quando? em que dia?' (transcrição de Guérios):

(55) a. há(k) tórú nim we

b. há(k) djinim we

Observe-se em (55)b. a presença de nim com o morfema dji, provável empréstimo da palavra 'dia' do Português.

Em Krenak as palavras interrogativas ocorrem predominantemente em posição inicial da oração:

(56) hakre krak wip

onde faca jazer

onde está a faca?

(57) inãy $\varepsilon$ mũy ne?

quem ? ir Fut

quem vai?

(58) Pam-ñm hoti pr̃m

Indef-Q você querer

(59) tãy tarutembrãn hoti a-ñ̃n ne?

quanto dia você 2sg-vir Fut

o que você quer?

quantos dias você virá?

(60) kõñm a -kruk pr̃m

qual 2sg-filho querer qual seu filho quer?

(61) Pam-ñ̃m we nãy ti puk Ti Indef-Q Causa ele ? chorar PresCont Por que ele está chorando?

Porém são também encontradas na posição após o sujeito, como nos seguintes dados:

(62) nã̃ kõñm pr̃m ele qual querer qual ele quer?
(63) hoti tãy ?am pri $m$ você quanto Indef querer você, quanto(s) quer? 


\subsection{Orações Imperativas}

No material analisado é possível distinguir três tipos de imperativos: o imperativo, o exortativo e o permissivo.

\subsubsection{Imperativo}

As formas imperativas são usadas com referência ao ouvinte (segunda pessoa). Não encontramos marcas especiais de imperativo positivo, exceto, possivelmente, a ausência da consoante final nos verbos mũy 'ir' e nỉ 'vir. No caso de verbos intransitivos o sujeito de segunda pessoa do singular não é expresso, ocorrendo o simples radical verbal:

(64) jani mũ

na frente ir

(65) $\tilde{\text { nI }} \mathrm{kr \varepsilon}$

vir aqui

vá na frente!

venha cá!

(66) t tjik

desça!

(67) mbã

saia!

É freqüente a repetição do verbo, notadamente se o mesmo vem acompanhado de algum modificador:

(68) morõm mũ peijãw kitot depressa ir feijão cozinhar vá depressa cozinhar feijão!
(69) mũ mrom mũ

ir depressa ir

vá, vá depressa!

Quando o comando é dirigido a mais de uma pessoa, usa-se o pronome ãndjuk 'vocês', em geral acompanhado de mbi $\sim \mathbf{n d i}$ 'todos' :

(70) ãndjuk mbindi mbãy

vocês todos sair

saiam vocês todos!

Com verbos transitivos o objeto direto é obrigatoriamente expresso e, no caso de alguns verbos, o sujeito de segunda pessoa do singular é marcado pelo prefixo a- ' $2^{\mathrm{a}}$ p.':

(71) ki-jẽm ma a-pok

3-casa porta 2 sg-fechar

feche a porta [buraco] da casa!
(72) kõn 3эp mbut

Indef beber parar

pare de beber isto! 
142

A negação no imperativo é assinalada pelo morfema nũy, posposto ao verbo:

(73) mbãy nũy

sair Neg

(74) kõn 3op nũy

Indef beber Neg

não saia!

não beba isso!

\subsubsection{Exortativo}

Exprime-se por meio dos morfemas ñãw, noãm ou noãmo, traduzidos aqui por 'vamos', 0 qual ocorre isoladamente ou seguido por verbo:

(75) ñãw (JA)

vamos embora!

(76) nูãw ?amãngut

Exort comer

vamos comer!

(77) ñãw waizik tupi

Exort flecha fazer

vamos fazer flecha!

(78) nูãw peijãw ammben (MS)

Exort feijão tirar da vagem

vamos tirar o feijão da vagem!

(79) กูãmo hũm

Exort banhar

vamos banhar!

\subsubsection{Permissivo}

Exprime-se por meio do morfema inũy 'deixa', que é seguido pela oração ou ocupa a posição após o sujeito:

(80) inũy n̊ã̃ kõn pip

Perm ele isso ver

deixa ele ver isso!
(81) ñãy inũy kõn pip ele Perm isso ver deixa ele ver isso!

Também encontramos o uso de (ãn)tãw (cf. Português 'então') em construções que exprimem permissão: 
(82) ãntãw mũ

então ir

pode ir

\section{CONCLUSÃO}

Neste trabalho apresentamos uma descrição de aspectos morfossintáticos do Krenak, focalizando a estrutura das orações independentes. Sem a pretensão oferecer uma análise conclusiva sobre esses aspectos, nosso objetivo foi antes de tudo proceder à sistematização dos dados que coletamos, tendo em vista divulgá-los, tornando-os acessíveis aos Krenak e outros interessados, tarefa a que pretendemos dar continuidade em outras oportunidades.

\section{REFERÊNCIAS}

MANIZER, H.H. (1915). Jazyk Botokudov. Manuscritos Inéditos. Arquivo do Museu de Antropologia e Etnografia "Pedro o Grande" (Kunstkamera) da Academia de Ciências da Rússia. Fond K-1, Opis' 1. Sanct Peterburg.

MANIZER, H. H. (1916). "Botokudy (borun) po nabljudénijam vo vrémja prebyvánija sredí nikh v 1915 g.”. Doklad, tchítannyj v zasedánijakh Rosískogo Antropologuítcheskogo óbshestva. Ezhegódnik Rúskogo Antropologuítche-skogo Óbshestva, T. VI, Peterburg.

MANIZER, H. H. (1919). Les Botocudos. Archivos do Museu Nacional do Rio de Janeiro, Vol.XXII. Rio de Janeiro:Imprensa Nacional.Mansur Guérios, R. F. (1944). Botocudos do rio Doce. Manuscrito Inédito

RUDOLPH, B. (1909). Wörterbuch der Botokudensprache. Hamburg

SEKI, L. (1984). "Problemas no Estudo de uma Língua em Extinção". Boletim da ABRALIN No. 6:109118. Campinas:Unicamp.

.(1990). "Apontamentos para a Bibliografia da Língua Botocudo". In: L. Seki (org.) Estudos em Línguas Indígenas. Cadernos de Estudos Lingüísticos 18:115-142. Campinas:Unicamp.

.(2000). Os Krenak (Botocudo Borum) e sua língua. In: L. Miranda (ed.) Actas I Congreso de Lenguas Indígenas de Sudamérica. T. I:351-374. Lima:Universidad Ricardo Palma. 
144

\section{ANEXOS}

Como mencionado na introdução, incluímos aqui desenhos feitos por H. H. Manizer em 1915, durante sua estadia entre os Krenak. São cópias dos originais que fazem parte dos manuscritos do mencionado autor, conservados no Arquivo do Museu de Antropologia e Etnografia "Pedro o Grande" (Kunstkamera) da Academia de Ciências da Rússia (doravante Arquivo MAE-ACR). Os desenhos foram publicados no Anuário da Sociedade Russa de Antropologia (Manizer, 1916). Em cada caso são indicadas as duas fontes.

A breve descrição que acompanha os anexos I e II está baseada em Manizer (1919).

I. Pintura corporal.

Manizer, H. H. Manuscritos. Arquivo MAE-ACR, Fond K-1, Opis' 1, No. 416, f. 76

Manizer, H. H. (1916), p. 102

Em sua obra Les Botocudos Manizer (1919) informa que após cada banho os índios esfregavam ligeiramente no corpo uma pasta vermelha, preparada com urucum. Somente entre os Krenak ele observou as pinturas aqui reproduzidas. Aquelas mostradas em B eram feitas por meio de canudos (cf. A) com o suco de frutas ainda não maduras de jenipapo. Segundo o mencionado autor, os desenhos de círculos fechados e os semicírculos representavam, respectivamente, o couro da onça e o do surubim. Com uma ponta fina eram desenhados os "passos de pássaro", mostrados separadamente em C, e com o dedo eram feitas as linhas (D, E), bem como a pintura contornando os lábios, como indicada em E. (Manizer, 1919:252-253).

II. Cortes de cabelo.

Manizer, H. H. Manuscritos. Arquivo MAE-ACR, Fond K-1, Opis' 1, No. 416, f. 76

Manizer, H. H. (1916), p. 102.

Conforme Manizer, as mulheres traziam seus cabelos ou cortados curtos, ou conservados longos, ora caindo sobre as espáduas, ora erguidos sobre a cabeça ou sobre a nuca. Já no caso dos homens, os cabelos eram cortados curtos (Manizer, 1919:252).

III. Abrigo.

Manizer, H. H. Manuscritos. Arquivo MAE-ACR, Fond K-1, Opis' 1, No. 416, f. 75

Manizer, H. H. (1916), p. 94.

IV. Abrigo.

Manizer, H. H. Manuscritos. Arquivo MAE-ACR, Fond K-1, Opis' 1, No. 416, f. 74

Manizer, H.H. (1916), p. 95. 

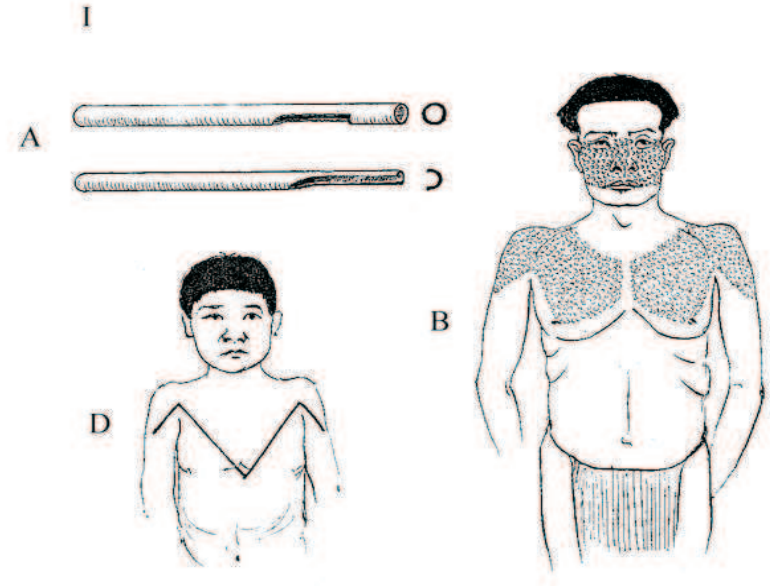

c
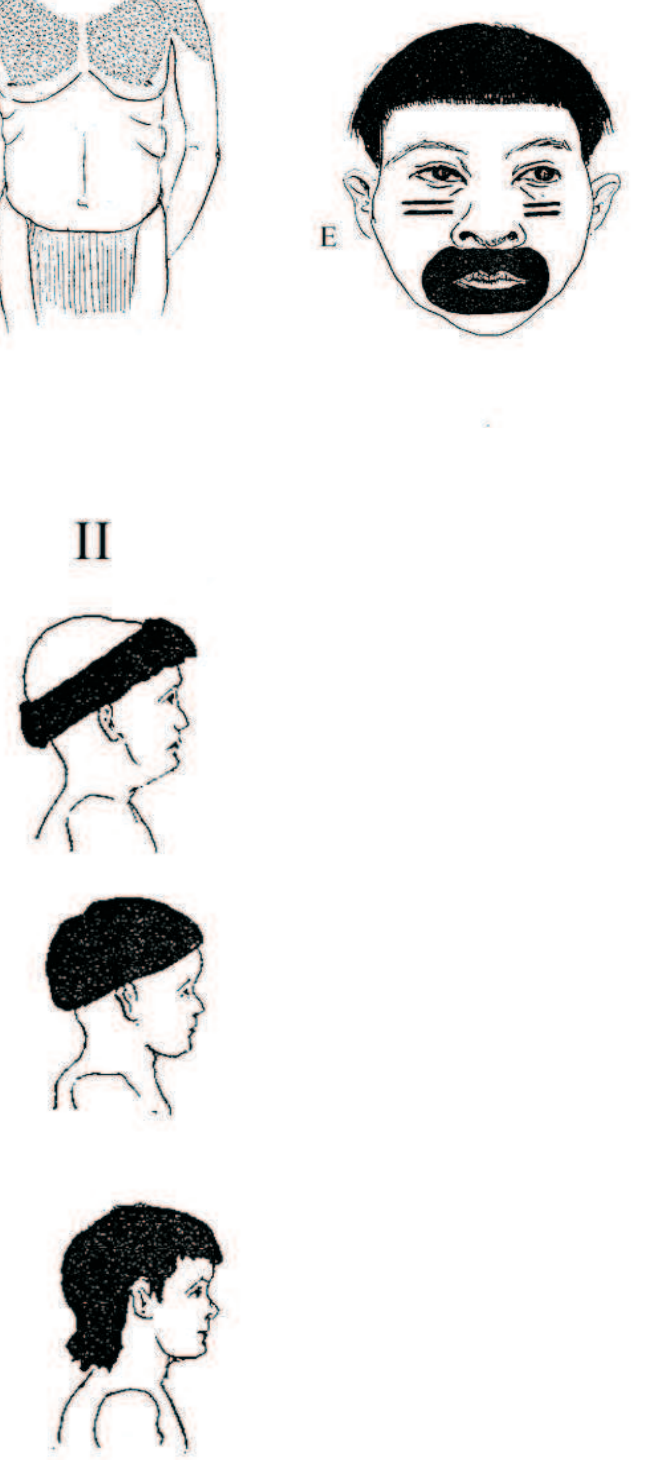

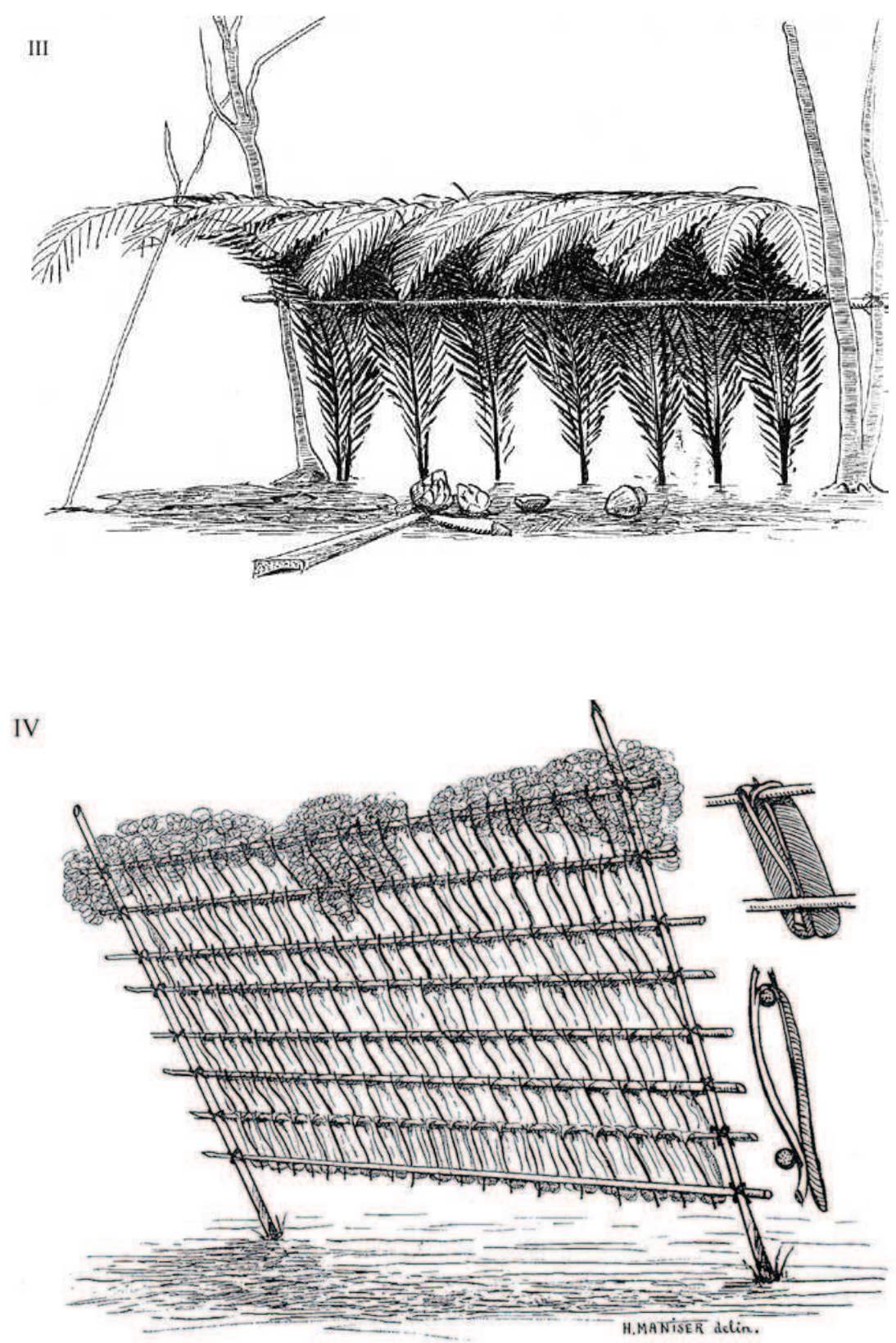